\title{
Perancangan Sistem Aplikasi Tracking Pendukung Touring Secara Real Time Menggunakan Firebase Berbasis Android (Studi Kasus Komunitas Motor Trigramyama Salatiga)
}

\author{
Tri Mulyono $^{1}$, Pratyaksa Ocsa Nugraha Saian ${ }^{2}$ \\ ${ }^{1,2}$ Universitas Kristen Satya Wacana; Jl. Diponegoro 52-60, Salatiga 50711, Indonesia, Fax. 321433 \\ ${ }^{3}$ Jurusan Teknik Informatika, FTI UKSW, Salatiga \\ e-mail: ${ }^{1}$ 672016179@ @student.uksw.edu, ${ }^{2}$ pratyaksa.ocsa@uksw.edu
}

\begin{abstract}
Trigramyama is a motorbike community that often holds touring activities outside the city with quite some members. With the large number of members participating, there are also many problems encountered when doing the touring, one of the problem is coordination between members when there are members who are separated from the group. This research will be designed a tracking system Android-based application in the Trigramyama motorbike community using firebase technology that utilizes the real-time database feature, besides this design uses GPS technology taken from the Google Maps API. this touring supporting tracking application allows all users to know the whereabouts of other members and also makes it easier to coordinate. The level of satisfaction from using this application reaches $85 \%$, from the results of the presentations it can be concluded that this application is following the needs of the Trigramyama motorcycle community.
\end{abstract}

Kata kunci: Firebase, Android, Tracking, Google Maps API

\begin{abstract}
Abstrak
Trigramyama merupakan komunitas motor yang seringkali mengadakan kegiatan touring ke luar kota dengan anggota yang cukup banyak. Banyaknya anggota yang ikut serta, maka banyak juga permasalahan yang ditemukan saat melakukan touring, salah satunya adalah koordinasi antar anggota ketika ada salah satu anggota yang terpisah dari rombongan. Pada penelitian ini akan dirancang aplikasi sistem tracking berbasis Android pada komunitas motor Trigramyama dengan menggunakan teknologi firebase yang memanfaatkan fitur realtime database, selain itu perancangan ini menggunakan teknologi GPS yang diambil dari API Google Maps. Adanya aplikasi tracking pendukung touring ini memungkinkan seluruh anggota untuk mengetahui keberadaan anggota lain dan juga memudahkan untuk melakukan koordinasi. Tingkat kepuasan dari pengunaan aplikasi ini mencapai $85 \%$, dari hasil presentasi yand ada dapat disimpulkan bahwa aplikasi ini sudah sesuai dengan kebutuhan komunitas motor Trigramyama.
\end{abstract}

Kata kunci: Firebase, Android, Tracking, Google Maps API 


\section{PENDAHULUAN}

Pada era ini teknologi dan informasi sangatlah mudah untuk diakses, salah satu bentuk dari perkembangan teknologi pada masa ini adalah smartphone (telepon pintar). Saat ini smartphone sudah dilengkapi dengan fasilitas-fasilitas canggih yang memungkinkan penggunanya melakukan apapun yang dibutuhkan, seperti fasilitas kamera berkualitas tinggi untuk mengambil foto dan video dengan hasil yang maksimal, ditambah fitur lainnya, seperti Global Positioning System (GPS), Wi-Fi, dan hotspot. Android digunakan untuk mempermudah manusia melakukan suatu aktivitas. Adanya smartphone Android banyak kegiatan manusia telah terbantu [1]. Fitur yang berada di dalam smartphone salah satunya GPS menjadikan proses tracking kendaraan menjadi lebih mudah, dengan hal tersebut sangat membantu saat melakukan perjalanan touring [2].

Pada studi kasus Komunitas motor Trigramyama yang berada di kota Salatiga. Komunitas motor Trigramyama ini merupakan komunitas motor custom yang seringkali mengadakan kegiatan touring keluar kota, dengan sejumlah 15 anggota . Aktivitas touring sendiri merupakan kegiatan berkendara dari satu kota ke kota lain secara bersama-sama [3]. Berdasarkan wawancara yang dilakukan oleh peneliti kepada ketua komunitas motor Trigramyama, peneliti mendapati selama ini Komunitas motor Trigramyama mengalami kesulitan dalam melakukan koordinasi antar anggota saat melakukan perjalanan touring, seperti ketika ada beberapa anggota yang terpisah dari rombongan, anggota yang salah mengambil rute dan miskomunikasi antar anggota yang mengakibatkan perjalanan touring menjadi terhambat.

Seiring berkembangnya teknologi sangat dimungkinkan dibangun sistem aplikasi pendukung touring dengan memanfaatkan fitur tracking. Tracking adalah kegiatan untuk mengetahui keberadaan kendaraan berdasarkan peta digital menggunakan fitur GPS. Titik koordinat yang didapat dari GPS akan disimpan secara realtime di Firebase, dan titik koordinat tersebut ditampilkan pada Google Maps sehingga memungkinkan untuk menampilkan live location. Adanya Google Map API maka tracking kendaraan saat melakukan touring lebih mudah. Setiap anggota bisa mengetahui keberadaan anggota yang lain dan juga memudahkan untuk melakukan koordinasi ketika ada anggota yang terpisah dari rombongan [4].

Berdasarkan latar belakang tersebut maka akan dilakukan penelitian untuk merancang sebuah aplikasi sistem tracking pada komunitas motor Trigramyama Salatiga berbasis Android menggunakan teknologi Firebase yang digunakan sebagai penyimpanan data secara realtime dan untuk mengautentikasi user menggunakan Email. Selain itu terdapat beberapa fitur lain juga seperti pengukur kecepatan, grup chat, notifikasi ketika ada yang melakukan request lokasi, dan juga GPS yang sudah terhubung melalui API Google Maps. Batasan masalah penelitian ini adalah aplikasi berupa aplikasi Android, aplikasi ini hanya bisa diakses oleh anggota komunitas Trigramyama, dan aplikasi hanya bisa diakses menggunakan jaringan internet.

\section{METODE PENELITIAN}

\subsection{Kajian Pustaka}

\subsubsection{Penelitian Terdahulu}

Terdapat beberapa penelitian yang dilakukan sebelumnya mengenai sistem tracking, salah satunya adalah penelitian yang dilakukan oleh Majid Rahardi, Lukito Edi Nugroho dan Ridi Fardian dengan judul "Perancangan Sistem grup tracking pada aktivitas touring berbasis mobile". Hasil dari penelitian ini adalah rancangan sistem pendukung aktivitas touring, berupa monitoring anggota touring dan group chat yang selanjutnya dapat diimplementasikan dalam sebuah aplikasi mobile [5].

Mulyono, et., al [Perancangan Sistem Aplikasi Tracking Pendukung Touring Secara Real Time Menggunakan Firebase Berbasis Android (Studi Kasus Komunitas Motor Trigramyama Salatiga)] 
Penelitian kedua dilakukan oleh Ramos Somya yang berjudul "Sistem Monitoring Kendaraan Secara RealTime Berbasis Android menggunakan Teknologi CouchDB di PT. Pura Barutama". Penelitian ini menghasilkan sebuah aplikasi sistem monitoring kendaraan secara RealTime yang dapat diakses oleh setiap unit produksi tanpa mendapatkan informasi dari unit kendaraan tersebut. Teknologi RealTime memungkinkan untuk membuat sistem pemantauan dengan jeda waktu terpendek. Saat kendaraan sedang melaju, informasi lokasi kendaraan akan langsung diketahui. Kemudian, teknologi tersebut dapat digunakan bersama dengan perangkat Android sehingga siapa pun dapat mengakses melalui perangkat seluler kapan pun dan di mana pun. Oleh karena itu solusi dari permasalahan yang ada adalah dengan membuat sistem monitoring kendaraan berbasis android yang dapat memantau lokasi kendaraan secara real time.[6].

Pada penelitian ketiga yang dilakukan Wahyu Kusuma dan Tity Septiani yang berjudul "Aplikasi Friend Tracker berbasis Android Smartphone menggunakan GPS Tracking". Penelitian ini membahas tentang implementasi GPS Tracking yang digunakan dalam aplikasi pencarian lokasi teman. Hasil akhir dari penelitian ini yaitu sebuah sistem tracking menggunakan perangkat Android yang berfungsi untuk mengetahui posisi teman yang telah terdaftar dalam friend list [7].

Berdasarkan penelitian-penelitian yang terkait pada perancangan ataupun pengembangan sistem aplikasi tracking dengan menggunakan GPS untuk mendapatkan titik koordinat lokasi dan penggunaan teknologi CouchDB yang berguna untuk penyimpanan data secara realtime sehingga memungkinkan dilakukannya tracking lokasi. Maka dari itu akan dilakukan perancangan aplikasi tracking dengan menggunakan teknologi GPS untuk mendapatkan titik lokasi dan kecepatan user saat berkendara. Firebase digunakan sebagai penyimpanan data secara realtime dan untuk memunculkan notifikasi serta autentifikasi user mengunakan Email, dan API Google Maps untuk menampilkan lokasi pada Google Maps berdasarkan titik koordinat, dengan studi kasus pada Komunitas Motor Trigramyama Salatiga.

\subsubsection{Android}

Android adalah sistem operasi mobile berbasis Linux, yang mencangkup sistem operasi dan Middleware. Fasilitas open source atau sistem operasi yang dapat dikembangkan oleh penggunan secara gratis, membuat banyak orang untuk mengembangkannya dengan inovasi yang semakin berkembang terhadap sistem operasinya maupun pada pembangunan aplikasi mobile tersebut. Maka tidak heran saat ini banyak pengembang yang membangun aplikasi mobile pada platfrom Android [8].

\subsubsection{Global Positioning System (GPS)}

Global Positioning System (GPS) merupakan sistem satelit navigasi dan pemosisian yang dapat terus menyediakan informasi posisi tiga dimensi, kecepatan, dan waktu diseluruh dunia, kapan pun dan di mana pun. GPS merupakan suatu alat yang digunakan oleh para nelayan untuk menandai lokasi dimana ikan-ikan sering berkumpul sehingga dapat digunakan pola sebaran ikan yang teratur[9].

\subsubsection{Firebase Realtime Database}

Firebase Realtime Database adalah database cloud. Data disimpan di dalam format JSON dan disinkronkan ke setiap klien yang terhubung secara realtime. Firebase biasanya digunakan pada aplikasi realtime. Ketika terjadi pembaruan data, maka aplikasi yang terhubung pada Firebase akan secara otomatis menerima pembaruan data . Firebase realtime database adalah basis data nonSQL dan karena itu memiliki optimalisasi dan fungsionalitas yang berbeda dibandingkan dengan basis data relasional [10]. 


\subsubsection{Application Program Interface (API)}

Application Progamming Interface (API) adalah dokumentasi yang berisi interface, fungsi, kelas, struktur dan sebagainya. Yang digunakan untuk membangun perangkat lunak. Dengan menggunakan API ini, programmer dapat dengan mudah membongkar perangkat lunak, dan kemudian mengembangkan atau mengintegrasikannya dengan perangkat lunak lain. API memungkinkan aplikasi untuk berinteraksi dan berinteraksi dengan aplikasi lain. Google juga menyediakan layanan Google Maps API. Pengembang dapat mengintegrasikan Google Maps $A P I$ ke situs web mereka dengan menambahkan data penunjuk mereka sendiri. Bahasa pemrograman yang digunakan oleh Google Maps termasuk HTML, Javascript, AJAX dan XML [11].

\subsection{Metode Penelitian}

Metode penelitian adalah prosedur atau langkah sistematis dalam melakukan pengamatan secara benar melalui tahapan yang disusun secara ilmiah untuk mencari, menyusun, menganalisis, dan menyimpulkan data sehingga dapat digunakan untuk menemukan, mengembangkan, dan menguji kebenaran suatu ilmu [12].

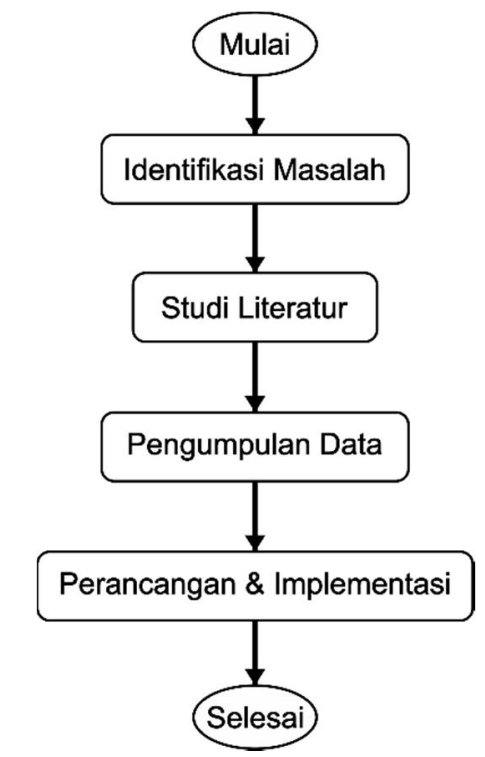

Gambar 1. Tahapan Penelitian [13].

Gambar 1 merupakan tahapan-tahapan yang dilakukan dalam perancangan sistem aplikasi tracking pendukung touring tersebut:

1. Identifikasi masalah. Pada tahapan ini dilakukan pengidentifikasian masalah yang ada. Permasalahan yang ada pada penelitian ini adalah dimana anggota Komunitas Trigramyama masih mengalami kesulitan dalam melakukan koordinasi saat melakukan kegiatan touring.

2. Studi literatur. Pada tahapan kedua dilakukan pengumpulan data dari penelitian sebelumnya, dari berbagai literatur dan dokumen, seperti buku dan jurnal yang mendukung penelitian ini.

3. Pengumpulan data. Tahapan ini dilakukan pengumpulan data dengan metode wawancara dan observasi. Sumber data yang digunakan pada penelitian ini berupa data primer yang diperoleh secara langsung dari sumber. Pada tahap pengumpulan data ini, data primer diperoleh melalui wawancara atau tanya jawab dengan Bapak Adi Widoyo selaku ketua dari komunitas motor Trigramyama Salatiga.

4. Perancangan dan implementasi. Pada tahapan ini dilakukan dalam perancangan dan implementasi pada aplikasi tracking ini menggunakan metode pengembangan Prototype. 


\subsubsection{Metode Pengembanagan System}

Metode Prototype merupakan metode pengembangan perangkat lunak, yang berupa model fisik kerja sistem dan berfungsi sebagai versi awal dari sistem. Metode prototype ini akan menghasilkan prototype sistem sebagai perantara pengembang dan pengguna agar dapat berinteraksi dalam proses kegiatan pengembangan sistem informasi. Agar proses pembuatan prototype ini berhasil dengan baik adalah dengan mendefinisikan aturan-aturan pada tahap awal, yaitu pengembang dan pengguna harus satu pemahaman bahwa prototype dibangun untuk mendefinisikan kebutuhan awal. Prototype akan dihilangkan atau ditambahkan pada bagiannya sehingga sesuai dengan perencanaan dan analisis yang dilakukan oleh pengembang sampai dengan uji coba dilakukan secara simultan seiring dengan proses pengembangan [14].

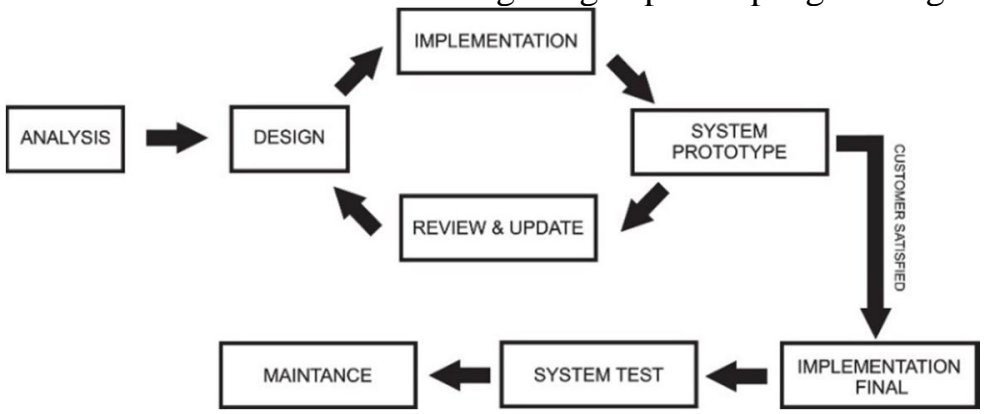

Gambar 2. Tahapan Penelitian [15]

Tahapan - tahapan pengerjaan penelitian yang akan digunakan pada Perancangan Sistem Aplikasi Tracking Pendukung Touring pada Gambar 2 dapat dijelaskan sebagai berikut:

1. Tahapan analisis. Pada tahapan ini ialah untuk mendapatkan semua informasi tentang permasalahan yang terjadi, dengan cara melakukan wawancara dan juga observasi pada pihak yang terkait untuk menggali informasi yang diperlukan agar dapat merekomendasikan sistem baru yang lebih efektif dan efisien.

2. Desain, pada tahap ini akan dilakukan desain sistem aplikasi yang digambarkan dalam bentuk UML diagram berdasarkan analisis yang sudah dilakukan.

3. Implementasi, pada tahapan ini akan dilakukan implementasi untuk pengkodean dalam bentuk bahasa pemrograman Java dengan menggunakan platform Android Studio.

4. Sistem Prototype, ketika sudah dilakukan implementasi maka akan di cek kesesuaian dengan alur perancang, jika aplikasi prototype tidak sesuai dengan yang diharapkan oleh client maka akan melakukan review dan update ulang sesuai permintaan client dengan melakukan pengkodean untuk memperbaiki kesalahan fitur maupun implementasi dalam sistem tracking tersebut.

5. Final implementasi. aplikasi sistem informasi yang sudah sesuai dengan keinginan client maka tidak perlu perbaikan lebih lanjut. Pada tahap ini aplikasi sudah sesuai dengan kebutuhan fitur sistem informasi tracking.

6. Sistem Test. Pada tahapan ini akan dilakukan pengujian sistem aplikasi menggunakan testing Alpha dan testing beta. Testing Alpha dilakukan menggunakan metode black box, untuk melakukan pengujian fungsi pada aplikasi. Testing beta dilakukan dengan menyebar kuisoner pada 15 anggota komunitas Trigramyama Salatiga.

\subsubsection{Arsitektur Sistem}

Arsitektur sistem merupakan model konseptual yang mendefinisikan struktur, perilaku dari suatu sistem. Tujuannya adalah merancang struktur untuk memenuhi kebutuhan pengguna. 


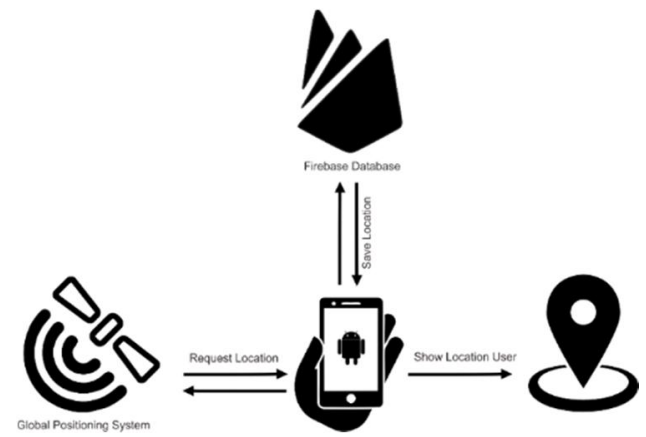

Gambar 3. Arsitektur Sistem

Pada gambar 3 menunjukkan tahap perancangan arsitektur dari sistem tracking pendukung touring, untuk memudahkan pemahaman alur kerja. Ketika anggota melakukan suatu perintah, maka perintah akan diproses di dalam smartphone, yang dimana smartphone harus tersambung dengan jaringan internet terlebih dahulu. Komponen GPS digunakan untuk mencari atau menemukan titik koordinat lokasi dari keberadaan perangkat smartphone, setelah titik koordinat lokasi ditemukan maka titik koordinat akan disimpan ke dalam Firebase secara realtime ketika sudah tersimpan, maka smartphone yang melakukan tracking tersebut sudah dapat menampilkan lokasi pada Google Maps dalam aplikasi.

\subsubsection{Use Case Diagram}

Perancangan Desain sistem aplikasi dibuat berdasarkan identifikasi masalah yang sudah ada, desain digambarkan dalam bentuk UML diagram diantaranya yaitu: Use case diagram, Actvity diagram dan Sequence diagram. Use case diagram, berfungsi untuk menggambarkan sistem dengan memasukkan fungsi yang ada pada subsistem yang bekerja dalam alur sehingga dapat menjelaskan hubungan aktor dalam menjelaskan sistem aplikasi.

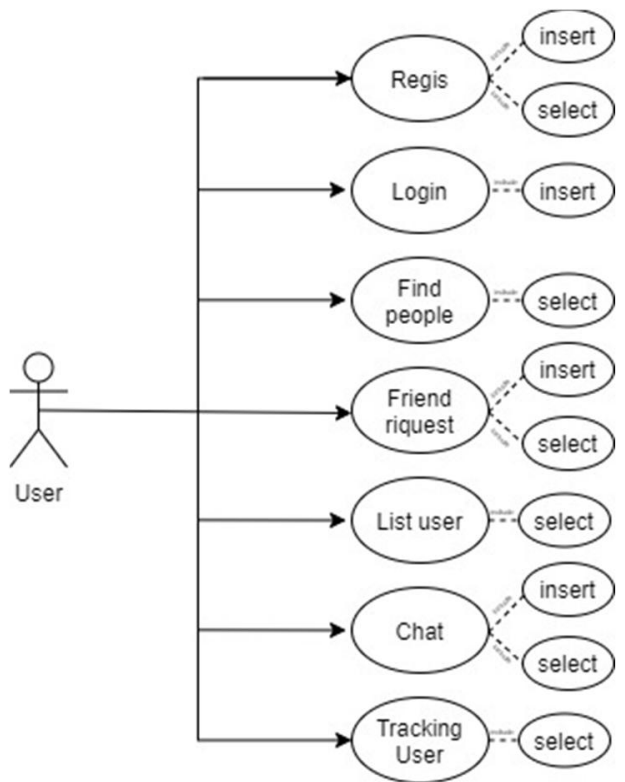

Gambar 4. Use Case Diagram

Pada gambar 4 menunjukkan sistem ini terdapat aktor User yang mengakses aplikasi dengan menggunakan perangkat Android yang tersambung pada Firebase Database Realtime, akses yang dimiliki user dalam aplikasi ini yaitu (login, register, find people, friend request, list

Mulyono, et., al [Perancangan Sistem Aplikasi Tracking Pendukung Touring Secara Real Time Menggunakan Firebase Berbasis Android (Studi Kasus Komunitas Motor Trigramyama Salatiga)] 
user, chat, tracking user) secara otomatis sistem ini mengirimkan koordinat lokasi yang akan langsung disimpan pada Firebase.

\subsubsection{Activity Diagram}

Activity Diagram digunakan untuk menjelaskan alur pengguna sistem dalam aplikasi.

Dalam aplikasi tracking ini terdapat aktivitas yang dapat dideskripsikan dari pengguna dengan aplikasi. Proses inti dari aplikasi tracking pendukung touring ini adalah proses tracking anggota komunitas.

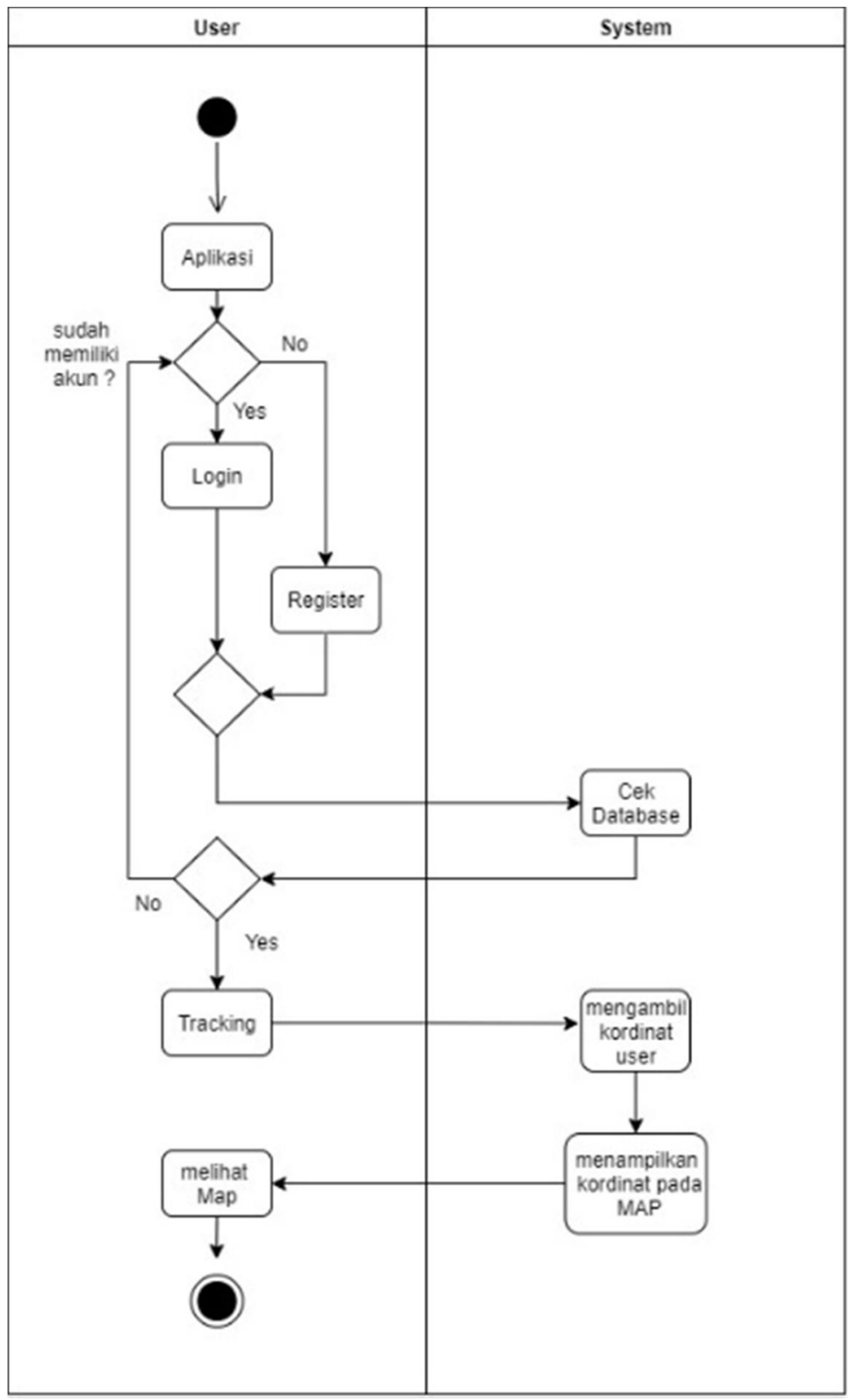

Gambar 5. Activity Diagram 
Pada Gambar 5 menunjukkan proses User untuk melakukan kegiatan tracking, user harus melakukan login dan mengaktifkan GPS untuk diambil kordinatnya dikarenakan activity membutuhkan sebuah informasi lokasi, supaya dapat ditampilkan lokasi pada map.

\subsubsection{Sequence Diagram}

Sequence Diagram digunakan untuk mennggambarkan skenario atau rangkaian langkah - langkah yang dilakukan user dari sebuah aplikasi.

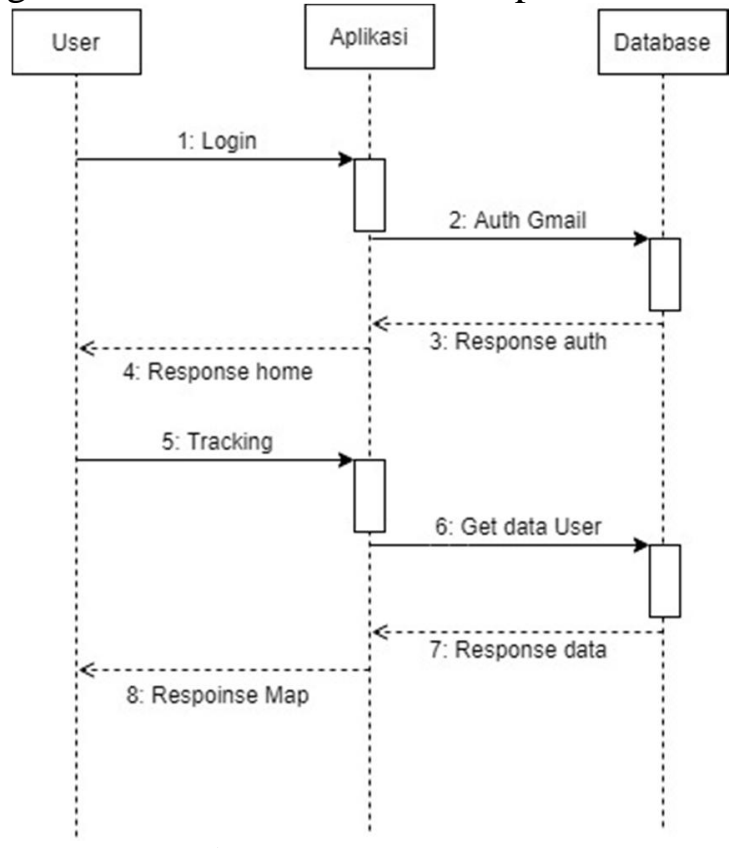

Gambar 6. Sequence Diagram

Pada Gambar 5, menunjukkan Proses user menggunakan fungsi tracking. Sequence diagram berfungsi untuk memberikan gambaran fungsionalitas dari use case.

\section{HASIL DAN PEMBAHASAN}

\subsection{Tampilan Aplikasi}

Tampilan aplikasi merupakan tampilan visual yang berada di dalam sebuah aplikasi untuk menghubungkan antara sistem dengan pengguna. Setelah dilakukan beberapa tahap perancangan, hasil yang telah dicapai adalah berupa aplikasi tracking pendukung touring berbasis Androit, pada Tabel 1 merupakan tampilan aplikasi yang dirancang pada penelitian ini.

Mulyono, et., al [Perancangan Sistem Aplikasi Tracking Pendukung Touring Secara Real Time Menggunakan Firebase Berbasis Android (Studi Kasus Komunitas Motor Trigramyama Salatiga)] 
Tabel 1. Tampilan Aplikasi dan Tampilan Firebase Database

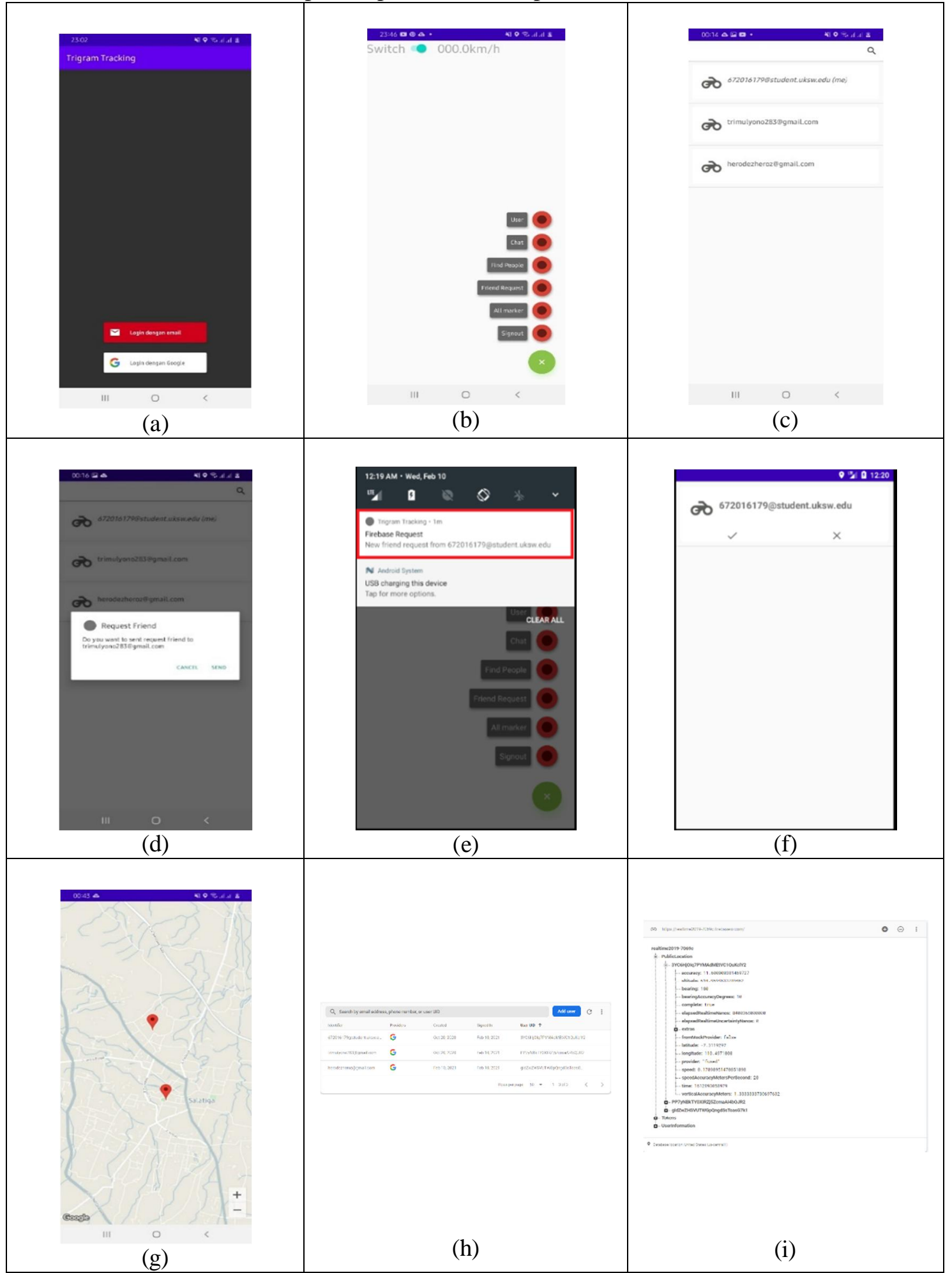

Gambar a merupakan halaman login, halaman ini digunakan oleh user untuk melakukan login. Login pada aplikasi ini harus menggunakan email yang sudah terdaftar di dalam sistem, apabila user belum memiliki akun maka diwajibkan untuk melakukan pendaftaran akun.

Mulyono, et., al [Perancangan Sistem Aplikasi Tracking Pendukung Touring Secara Real Time Menggunakan Firebase Berbasis Android (Studi Kasus Komunitas Motor Trigramyama Salatiga)] 
Gambar $b$ merupakan halaman home atau tampilan utama sesudah user berhasil melakukan login. Pada halaman home terdapat fitur berupa speedometer dan floating action menu. Di dalam floating action menu ini juga terdapat beberapa menu yang memiliki fungsi dan peranan yang berbeda, diantaranya: user, chat, find people, friend request, all marker, dan signout.

Gambar $c$ dan $d$ merupakan halaman menu find people, halaman menu ini berisikan list para anggota yang sudah terdaftar di dalam Firebase. Dalam menu find people, user dapat mengirimkan request friend kepada user lain.

Gambar e merupakan notifikasi yang diterima user ketika mendapatkan permintaan perteman dari user lain.

Gambar $f$ merupakan menu friend request. menu ini menampilkan list permintaan pertemanan dari user lain dan user dapat menerima atau menolak permintaan pertemanan tersebut.

Gambar $g$ merupakan halaman menu all marker yang berfungsi untuk menampilkan live location seluruh user online yang sudah saling berteman. Posisi user secara otomatis akan memperbarui posisi letaknya dikarenakan menggunakan realtime database jadi user dapat memonitoring posisi user lainnya.

Gambar $h$ merupakan tampilan yang berada di dalam Firebase Database, Pada halaman ini berfungsi untuk menampilkan dan menjelaskan mengenai user yang sudah melakukan pendaftaran, maka email dan password akan secara otomatis masuk ke Firebase Database.

Gambar $i$ merupakan tampilan yang berada di dalam Firebase Database, halaman ini menampilkan rangkaian atau struktur database untuk data user di dalam Firebase pada aplikasi tracking pendukung touring. Database Firebase yang digunakan aplikasi ini sudah berbentuk JavaScript Object Notation (Json) jadi sudah tidak menggunakan sistem tabel lagi. Pada halaman ini juga menampilkan data latitude dan longitude yang dimana data selalu berubah sesuai titik koordinat yang didapat, data pada latitude dan longitude akan otomatis melakukan pembaruan ketika user berpindah lokasi.

Tabel 2. Kode Program Ketika Lokasi User Berpindah

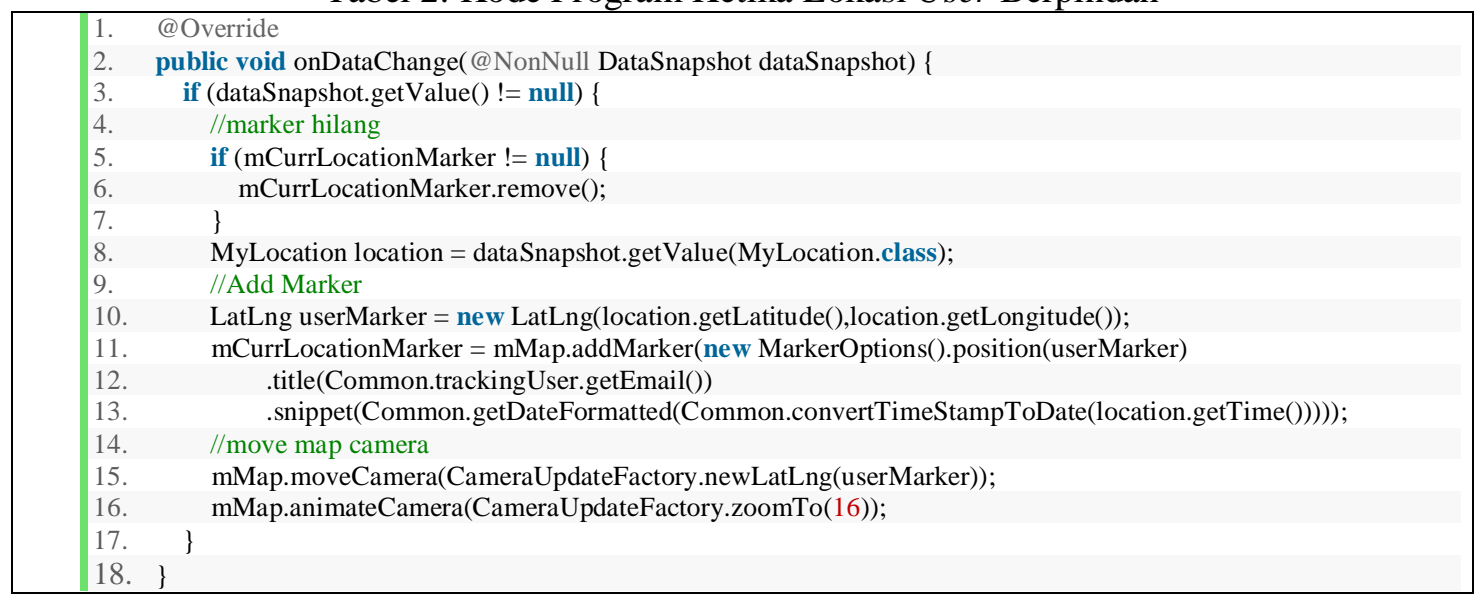

Tabel 2 merupakan kode program yang berfungsi untuk mengambil posisi user, ketika posisi user berpindah maka akan secara otomatis melakukan upload latitude, longitude ke dalam Firebase. Pada fungsi ini akan membaca perubahan data di Firebase, dimana data yang terbaca adalah user yang sudah terhubung dengan smartphone user lain. Seperti fungsi pada baris 2 onDataChange akan dieksekusi ketika data di Firebase berubah dan mengambil data Snapshot

Mulyono, et., al [Perancangan Sistem Aplikasi Tracking Pendukung Touring Secara Real Time Menggunakan Firebase Berbasis Android (Studi Kasus Komunitas Motor Trigramyama Salatiga)] 
yang terbaru untuk digunakan memindah marker pada map. Pada baris ke 3 - 17 akan melakukan eksekusi ketika data Snapshot tidak kosong, pada baris $5-7$ berfungsi untuk menghapus marker yang sudah tampil di map, baris 10 digunakan untuk mengatur latitude, longitude yang diambil berdasarkan data pada baris 8, baris 11- 13 berfungsi untuk menampilkan marker, kemudian pada baris 15 - 16 berfungsi untuk mengatur posisi kamera Google Map sesuai dengan marker.

Tabel 3. Kode Program Request Lokasi User

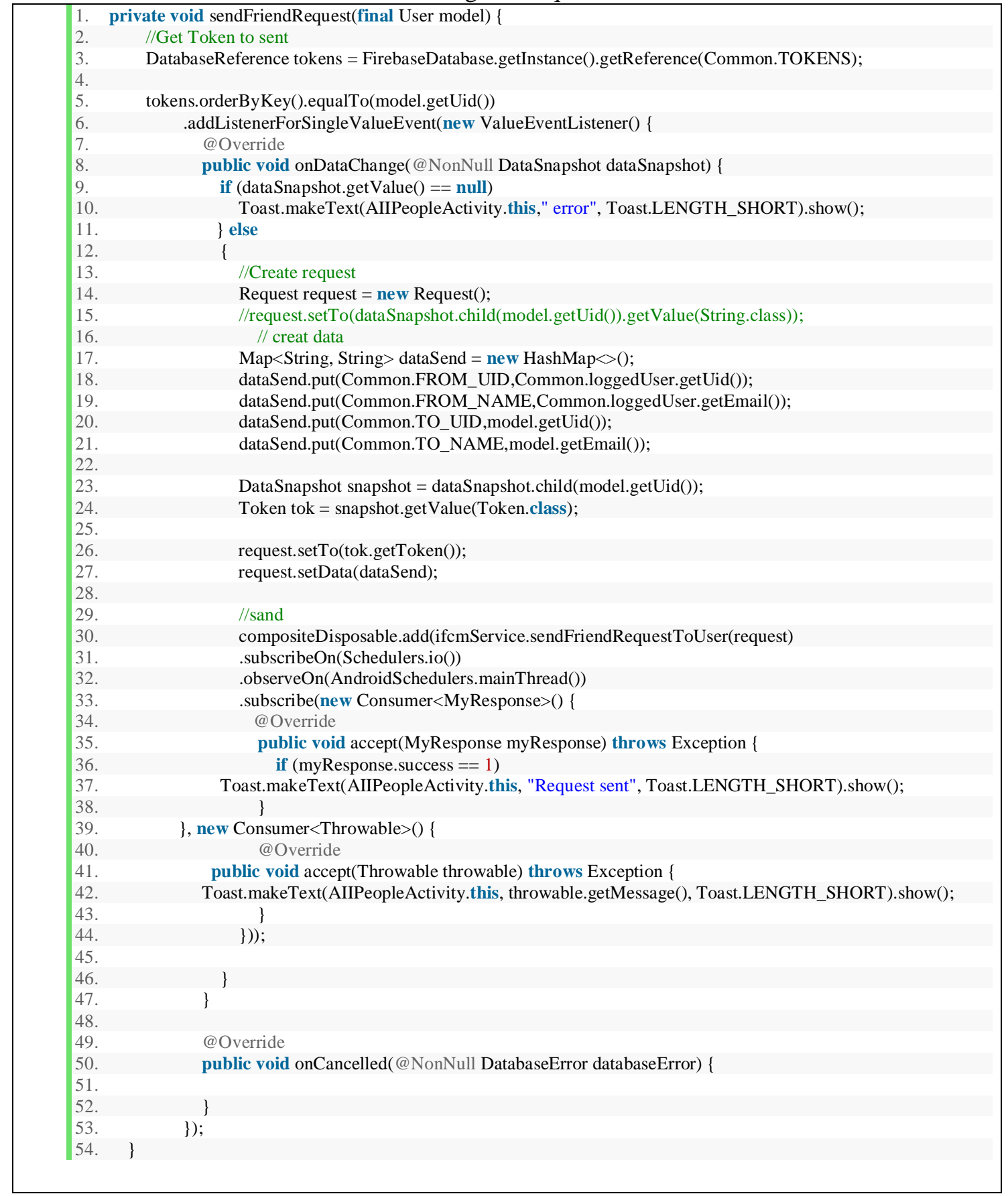

Mulyono, et., al [Perancangan Sistem Aplikasi Tracking Pendukung Touring Secara Real Time Menggunakan Firebase Berbasis Android (Studi Kasus Komunitas Motor Trigramyama Salatiga)] 
Tabel 3 merupakan Kode program yang berfungsi untuk request lokasi kepada user lain dimana untuk mendapatkan ijin melakukan tracking kepada user, harus saling mengirimkan permintaan pertemanaan (request friend). Baris 8-11 onDataChange akan mengecek data di dalam data Snapshot kosong atau tidak, jika kosong maka akan muncul peringatan atau (alert), pada baris $14-27$ akan membuat inisialisasi request dan membuat data request, setelah itu pada baris 30 - 54 merupakan fungsi untuk mengirimkan request friend ke Firebase, selanjutnya apabila data request terkirim akan mendapatkan pemberitahuan request berhasil atau gagal.

\subsection{Pengujian Sistem}

Pengujian sistem dilakukan untuk memastikan sistem berjalan dengan baik atau belum. Pengujian sistem pada aplikasi ini menggunakan testing Alpha dan testing Beta. Testing Alpha dilakukan menggunakan metode Black Box, dengan poin-poin pengujian yang dapat dilihat pada Tabel 4.

Tabel 4. Pengujian Alpha Aplikasi Tracking Pendukung Touring

\begin{tabular}{|c|c|c|c|c|c|}
\hline No & Titik Pengujian & Data input & Data Output & Hasil Uji Coba & $\begin{array}{l}\text { Status } \\
\text { Uji }\end{array}$ \\
\hline 1 & $\begin{array}{l}\text { Halaman login } \\
\text { aplikasi android }\end{array}$ & $\begin{array}{l}\text { Email dan } \\
\text { password }\end{array}$ & - & $\begin{array}{l}\text { Berhasil login ke } \\
\text { dalam aplikasi }\end{array}$ & valid \\
\hline 2 & Menu find people & - & $\begin{array}{l}\text { Menampilkan list } \\
\text { data user yang } \\
\text { sudah masuk ke } \\
\text { dalam_aplikasi }\end{array}$ & $\begin{array}{l}\text { Aplikasi berhasil } \\
\text { menampilkan data } \\
\text { user pada menu find } \\
\text { people. }\end{array}$ & valid \\
\hline 3 & $\begin{array}{l}\text { Request friend } \\
\text { pada menu find } \\
\text { people }\end{array}$ & - & $\begin{array}{l}\text { Sistem } \\
\text { memberikan pesan } \\
\text { bahwa request } \\
\text { telah terkirim }\end{array}$ & $\begin{array}{l}\text { Berhasil melakukan } \\
\text { request friend }\end{array}$ & valid \\
\hline 4 & $\begin{array}{l}\text { Melakukan } \\
\text { chatting }\end{array}$ & $\begin{array}{l}\text { Pesan yang } \\
\text { akan } \\
\text { dikirim } \\
\end{array}$ & \begin{tabular}{ll}
\multicolumn{2}{l}{ Menampilkan } \\
pesan yang \\
diterima
\end{tabular} & $\begin{array}{ll}\text { Berhasil } & \text { mengirim } \\
\text { dan } & \text { menerima } \\
\text { pesan } & \\
\end{array}$ & valid \\
\hline 5 & $\begin{array}{l}\text { Menu friend } \\
\text { request }\end{array}$ & - & $\begin{array}{l}\text { Menampilkan data } \\
\text { Request yang } \\
\text { masuk }\end{array}$ & $\begin{array}{l}\text { Berhasil melakukan } \\
\text { verifikasi pada } \\
\text { request friend yang } \\
\text { masuk }\end{array}$ & valid \\
\hline 6 & Menu all marker & - & $\begin{array}{l}\text { Menampilkan data } \\
\text { lokasi kemudiaan } \\
\text { diimplementasikan } \\
\text { ke google map }\end{array}$ & $\begin{array}{l}\text { Aplikasi berhasil } \\
\text { menampilkan } \\
\text { semua marker user }\end{array}$ & valid \\
\hline
\end{tabular}

Merujuk pada pengujian alpha pada Tabel 1 didapatkan hasil jika sistem sudah sesuai dengan kebutuhan pengguna, setelah aplikasi jadi maka akan dilakukan beta testing kepada 15 anggota komunitas motor Trigramyama Salatiga, dengan memberikan kuesioner. Berikut adalah pertanyaan yang berada dalam kuesioner yang akan dibagikan:

1. User interface pada aplikasi sudah baik.

2. Pengoperasian aplikasi cukup mudah.

3. Tracking pada aplikasi sudah berfungsi dengan baik.

4. Apakah data koordinat lokasi otomatis berganti setiap berjalan?

5. Apakah posisi lokasi yang ditunjukan sudah akurat?

6. Fitur chatting pada aplikasi dapat digunakan dengan baik. 
7. Apakah anda puas dengan hasil sistem aplikasi tracking pendukung touring yang dirancang?

Sekala penilaian setiap pertanyaan yaitu $1-5$.

- Sangat Setuju = 5

- Setuju = 4

- Cukup Setuju = 3

- Tidak Setuju $\quad=2$

- Sangat Tidak Setuju = 1

Tabel 5. Jumlah Jawaban kuesioner

\begin{tabular}{|c|c|c|c|c|c|}
\hline \multirow{2}{*}{ Pertanyaan } & \multicolumn{5}{|c|}{ Jumlah Jawaban } \\
\cline { 2 - 6 } & $\mathbf{1}$ & $\mathbf{2}$ & $\mathbf{3}$ & $\mathbf{4}$ & $\mathbf{5}$ \\
\hline $\mathbf{1}$ & & $\mathbf{2}$ & $\mathbf{4}$ & $\mathbf{2}$ & $\mathbf{5}$ \\
\hline $\mathbf{2}$ & & & $\mathbf{2}$ & $\mathbf{7}$ & $\mathbf{6}$ \\
\hline $\mathbf{3}$ & & & $\mathbf{3}$ & $\mathbf{6}$ & $\mathbf{6}$ \\
\hline $\mathbf{4}$ & & & $\mathbf{4}$ & $\mathbf{7}$ & $\mathbf{4}$ \\
\hline $\mathbf{5}$ & & & $\mathbf{4}$ & $\mathbf{3}$ & $\mathbf{8}$ \\
\hline $\mathbf{6}$ & & $\mathbf{1}$ & $\mathbf{4}$ & $\mathbf{6}$ & $\mathbf{4}$ \\
\hline $\mathbf{7}$ & & & $\mathbf{2}$ & $\mathbf{7}$ & $\mathbf{6}$ \\
\hline
\end{tabular}

Tabel 2 merupakan data jawaban dari 15 anggota komunitas motor Trigramyama Salatiga yang sudah mengisi kuesioner dalam bentuk skala Likert. Skala Likert digunakan untuk menghitung persentase dari setiap pertanyaan. Berikut ini adalah rumus persamaan skala Likert [16]:

$$
\rho=\frac{f}{n} \times 100 \%
$$

Keterangan: $\rho=$ Persentase, $f=$ Frekuensi jawaban angket, $n=$ Jumlah skor ideal, $100=$ Bilangan tetap.

Tabel 6. Hasil Persentasi Kuesioner

\begin{tabular}{|c|c|c|c|c|c|c|c|}
\hline \multirow{2}{*}{ Pertanyaan } & \multicolumn{5}{|c|}{$\begin{array}{c}\text { Sekala penilaian *Frekuensi } \\
\text { Kemunulan data }\end{array}$} & $\begin{array}{c}\text { Total } \\
\text { Sekor }\end{array}$ & $\begin{array}{c}\text { IKK } \\
(\%)\end{array}$ \\
\cline { 2 - 8 } & 1 & 2 & 3 & 4 & 5 & & \\
\hline 1 & & 4 & 12 & 8 & 24 & 49 & $65 \%$ \\
\hline 2 & & & 6 & 28 & 30 & 64 & $85 \%$ \\
\hline 3 & & & 9 & 24 & 30 & 63 & $84 \%$ \\
\hline 4 & & & 12 & 28 & 20 & 60 & $80 \%$ \\
\hline 5 & & & 12 & 12 & 40 & 64 & $85 \%$ \\
\hline 6 & & 2 & 12 & 24 & 20 & 54 & $77 \%$ \\
\hline 7 & & & 6 & 28 & 30 & 64 & $85 \%$ \\
\hline
\end{tabular}

Sekala Reting kepuasan pengguna dari $0-100 \%$.

- Sangat Baik

$$
\begin{aligned}
& =61-100 \\
& =46-60
\end{aligned}
$$


- Cukup Baik = $\quad 31-45$

- Kurang Baik $\quad=16-30$

- Sangat Kurang Baik $\quad=0-15$

Berdasarkan perhitungan skala Likert yang dapat dilihat pada Tabel 3 mendapatkan hasil sebagai berikut: $65 \%$ responden mengatakan user interface aplikasi mobile Android yang dikembangkan sangat baik, $85 \%$ responden mengatakan aplikasi mudah dioperasikan, $84 \%$ responden mengatakan tracking pada aplikasi sudah berfungsi sangat baik, $80 \%$ responden menyatakan data koordinat lokasi sudah otomatis berganti setiap berjalan, $85 \%$ responden menyatakan posisi lokasi sudah ditunjukkan dengan akurat, $77 \%$ responden menyatakan fitur chatting sudah bisa digunakan dengan sangat baik, $85 \%$ responden menyatakan puas dengan hasil sistem aplikasi tracking pendukung touring yang dirancang.

\section{KESIMPULAN}

Berdasarkan penelitian dan pengujian sistem maupun hasil kuesioner dari anggota komunitas, menghasilkan $85 \%$ pengguna aplikasi sangat puas dengan aplikasi tracking yang dapat menampilkan posisi seluruh anggota dengan akurat. Sehingga sangat membantu dalam melakukan aktivitas touring dan memudahkan para anggota komunitas Trigramyama untuk melakukan koordinasi ketika ada salah satu anggota yang tertinggal dari rombongan.

\section{SARAN}

Adapun saran yang diperlukan adalah mengenai peningkatan terkait user interface, yang harus dikembangkan lagi sehingga membuat pengguna lebih nyaman dalam menggunakan aplikasi.

\section{DAFTAR PUSTAKA}

[1] E. Ismanto, M. Novalia, and P. B. Herlandy. 2017, "Pemanfaatan Smartphone Android Sebagai Media Pembelajaran Bagi Guru SMA Negeri 2,” J. Untukmu Negeri, Vol. 1, No. 1, pp. 42-47.

[2] I. O. Widyantara, I. G. A. K. Warmayana, and L. Linawati. 2015, "Penerapan Teknologi GPS Tracker Untuk Identifikasi Kondisi Traffik Jalan Raya,” Maj. Ilm. Teknol. Elektro, Vol. 14, No. 1, pp. 31-35.

[3] M. Rahardi, L. E. Nugroho, and R. Ferdiana. 2016, "Perancangan Aplikasi Pendukung Touring Berbasis Contextual Awareness," Semin. Nas. Teknol. Inf. dan Multimed. STMIK AMIKOM Yogyakarta, pp. 6-7.

[4] J. W. V. M. T. I Putu Dedy Sandana, "Rancang Bangun Aplikasi Mobile Tracking Dengan Menggunakan SMS Gateway Untuk Meningkatkan Keamanan pada PT. Artiduta Aneka Usaha."

[5] M. Rahardi, L. E. Nugroho, and R. Ferdiana. 2016, "Perancangan Sistem Group Tracking pada Aktivitas Touring Berbasis Android," Semin. Nas. Teknol. Inf. dan Multimed, pp. 6-7. 
[6] R. Somya. 2018, "Sistem Monitoring Kendaraan Secara Real Time Berbasis Android Menggunakan Teknologi CouchDB di PT. Pura Barutama," J. Nas. Teknol. dan Sist. Inf., vol. 4, no. 2, pp. 53-60.

[7] W. Kusuma and T. Septiani. 2013, "Aplikasi Friend Tracker Berbasis Android Smartphone Menggunakan GPS Tracking,” Semin. Nas. Teknol. Inf. dan Multimed., Vol. 1, No. 1, pp. 13-18.

[8] M. Ichwan, M. G. Husada, and M. Iqbal Ar Rasyid. 2013, "Pembangunan Prototipe Sistem Pengendalian Peralatan Listrik pada Platform Android," J. Inform., Vol. 4, No. 1, pp. 13-25.

[9] A. Rizal. 2018, “Pengenalan Teknologi Komputer,” Vol. 3, No. 3, pp. 6-12.

[10] M. Ilhami. 2017, "Pengenalan Google Firebase Untuk Hybrid Mobile Apps Berbasis Cordova," J. IT CIDA, Vol. 3, No. 124, pp. 16-29.

[11] M. S. Amri. 2010, “Membangun Sistem Navigasi Di Surabaya Menggunakan Google Maps Api,” Pens Its, Vol. 1, No. Proposal 2013, pp. 1-5.

[12] M. A. Ramdhani. 2013, "Metodologi Penelitian Dalam Riset Teknologi Informasi,"

[13] G. N. Mu'azd and S. Sriyanto. 2015, "Analisis dan Perancangan Sistem Informasi Penelitian Berbasis Website Menggunakan Fasilitas SMS Gateway (Studi Kasus di Teknik Industri Universitas Diponegoro),” None, Vol. 4, pp. 1-14.

[14] A. A. Pradipta, Y. A. Prasetyo, and N. Ambarsari. 2015, "Pengembangan Web ECommerce Bojana Sari Menggunakan Metode Prototype," e-Proceeding Eng., Vol. 2, No. 1, pp. 1042-1056.

[15] D. Purnomo. 2017, "Model Prototyping pada Pengembangan Sistem Informasi," J I M P - J. Inform. Merdeka Pasuruan, Vol. 2, No. 2, pp. 54-61

[16] T. Nempung, T. Setiyaningsih, and N. Syamsiah. 2015, "Otomatisasi Metode Penelitian Skala Likert Berbasis Web," No. November, pp. 1-8. 